\title{
Modernizing Yazd. Selective Historical Memory and the Fate of Vernacular Architecture. Costa Mesa, Mazda, 2005, 199 p., 67 cartes.
}

\section{Bernard Hourcade}

\section{(2) OpenEdition}

Journals

Édition électronique

URL : http://journals.openedition.org/abstractairanica/11342

DOI : 10.4000/abstractairanica. 11342

ISSN : 1961-960X

Éditeur :

CNRS (UMR 7528 Mondes iraniens et indiens), Éditions de l'IFRI

\section{Édition imprimée}

Date de publication : 15 mai 2007

ISSN : 0240-8910

\section{Référence électronique}

Bernard Hourcade, « Modernizing Yazd. Selective Historical Memory and the Fate of Vernacular Architecture. Costa Mesa, Mazda, 2005, 199 p., 67 cartes. », Abstracta Iranica [En ligne], Volume 28 | 2007, document 492, mis en ligne le 18 septembre 2007, consulté le 25 septembre 2020. URL : http:// journals.openedition.org/abstractairanica/11342; DOI : https://doi.org/10.4000/abstractairanica. 11342

Ce document a été généré automatiquement le 25 septembre 2020.

Tous droits réservés 


\title{
Modernizing Yazd. Selective Historical Memory and the Fate of Vernacular Architecture. Costa Mesa, Mazda, 2005, 199 p., 67 cartes.
}

\author{
Bernard Hourcade
}

Ce livre inaugure une collection (Urban Planning History of Iranian Cities) destinée à étudier les relations entre l'évolution du tissu et de l'urbanisme des villes d'Iran en relation avec les politiques mais surtout les cultures et sociétés. L'exemple de Yazd, qui possède le tissu ancien le plus typique du plateau iranien, est présenté depuis les origines jusqu'au percement des grandes avenues sous le gouvernement islamique, en montrant à l'aide de cartes détaillées comment chaque période produisait un espace bâti spécifique. Les études sur les relations entre société rurale et habitat sont nombreuses, mais c'est la première fois que cette problématique est appliquée de façon systématique à une ville. Le dernier chapitre analyse à partir de cartes la société yazdī en rapport avec le développement spatial récent de la ville. Ce livre très bien illustré de cartes et de photos intimement liées au texte, permet enfin de sortir de l'histoire urbaine centrée sur l'anecdotique ou les monuments historiques.

\section{INDEX}

Thèmes : 15.1. Iran 


\section{AUTEURS}

\section{BERNARD HOURCADE}

CNRS / Mondes iranien et indien - Paris 